Jan Schürnbrand

\title{
Organschaft im Recht der privaten Verbände
}

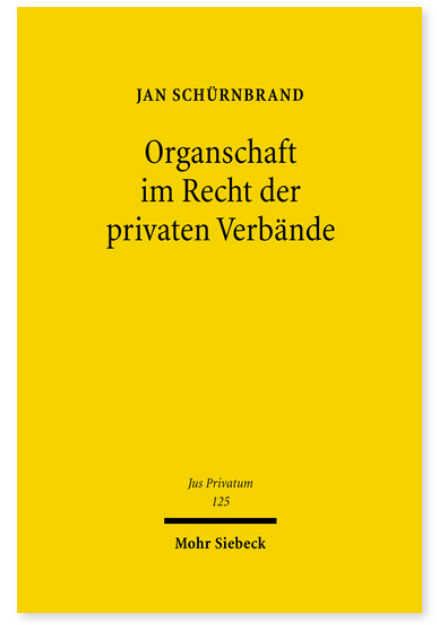

2007. XXI, 476 Seiten. JusPriv 125

ISBN 978-3-16-151202-5

DOI 10.1628/978-3-16-151202-5

eBook PDF 139,00 €

ISBN 978-3-16-149467-3

Leinen $139,00 €$
Nur mit Hilfe ihrer Organe und Organwalter können Gesellschaften und Vereine wie eine natürliche Person am Rechtsverkehr teilnehmen. Damit bildet die Organschaft eines der zentralen Rechtsinstitute des Verbandsrechts. Jan Schürnbrand arbeitet die Thematik umfassend auf und entwickelt allgemeine Lehren über das Organ. Im Vordergrund steht dabei zunächst die Frage, welche der am Verbandsleben beteiligten Einrichtungen überhaupt Organ des Verbandes ist. Im Rahmen eines induktiven Untersuchungsansatzes beleuchtet der Autor unter anderem den Abschlussprüfer und den Insolvenzverwalter näher und untersucht, ob die Rechtsstellung des anderen Vertragsteils beim Beherrschungsvertrag oder diejenige des Versammlungsleiters der Mitgliederversammlung als organschaftlich zu qualifizieren ist. Einen weiteren Schwerpunkt bildet sodann die rechtsformübergreifende Untersuchung praktischer Problemfelder. Nähere Behandlung finden dabei etwa die Organnachfolge, mithin die Frage nach dem Schicksal von Organen in Umwandlungsfällen, und das Phänomen der Doppelorganschaft, also der gleichzeitigen Tätigkeit eines Organwalters für zwei Verbände. Eingehende Ausführungen finden sich des Weiteren zur Lehre vom fehlerhaften und faktischen Organ, zum personengesellschaftsrechtlichen Grundsatz der Selbstorganschaft sowie zum Organstreit. Schließlich werden die Herausforderungen erörtert, die von organexternen Führungsgremien ausgehen, die als »Group Executive Committees«, »Aktionärsausschüsse« oder »Bereichsvorstände« zunehmend Verbreitung finden.

Jan Schürnbrand 1972-2016; Studium der Rechtswissenschaften in Konstanz, Poitiers und München; 2002 Promotion; 2007 Habilitation; Lehrstuhlvertretung an der Universität Erlangen-Nürnberg, ab 2012 Inhaber des Lehrstuhls für Bürgerliches Recht, Handels- und Gesellschaftsrecht und Rechtsvergleichung an der Eberhard Karls Universität Tübingen.

Jetzt bestellen:

https://mohrsiebeck.com/buch/organschaft-im-recht-der-privaten-verbaende-9783161512025?no_cache=1 order@mohrsiebeck.com

Telefon: +49 (0)7071-923-17

Telefax: $+49(0) 7071-51104$ 